\title{
Sustainability assessment of retail logistics solutions using external costs analysis: a case-study for the city of Antwerp
}

\author{
Konstantinos Papoutsis ${ }^{1,2^{*}}$, Wouter Dewulf ${ }^{1}$, Thierry Vanelslander ${ }^{1}$ and Eftihia Nathanail ${ }^{2}$
}

\begin{abstract}
Purpose: Policy implementation in the logistics sector might drive unexpected side-effects which sometimes undermine the performance of key economic activities of logistics operators, especially in areas such as transport service, sustainability of operations, etc. Especially for the latter, there is a lack of understanding how the sustainability performance if retail logistics solutions is impacted on by policy implementation and, in turn, by operators' responsive measures. This paper conducts a sustainability analysis of concrete innovative and already tested retail logistics solutions addressing the research question "what are the effects of retail logistics solutions on total costs and sustainability performance?"

Methods: The analysis relies on the development and application of an indicator-based framework based on the key sustainability components (economy, environment, society) and enriched by the addition of the transport component. The framework assesses three different scenarios together with a business-as-is one: Urban Consolidation Centre, Tethering and Shared Bus accompanied with a Strengths-Weaknesses analysis. Data are provided by an international food retailer operating within the city of Antwerp, Belgium, but conclusions can be generalized due to wider applicability of measures and solutions examined.
\end{abstract}

Results: External costs analysis shows that higher degree of internalization is achieved in the line-haul transport. Within an urban context, the measures that do not require significant initial investment and broad interventions are assessed as the most sustainable in our analysis. Tethering is the solution that indicates the highest sustainability score.

Conclusions: The impact of innovative and already tested solutions relies on a variety of factors: organizational, urban context, type of goods transported, engagement of stakeholders, etc.. In any case, innovation is crucial for urban retail logistics impacting on transport service, society, economy and environment. Any new retail business model should be designed with respect to cost efficiency and through a socially acceptable transition path.

Keywords: Retail, Sustainability, Logistics, External costs, UCC, Tethering, Shared bus, Antwerp

\section{Introduction}

The urban context represents a geographical area of challenges for transport and logistics activities, both in terms of logistics performance and sustainability. Around $74 \%$ of Europe's population lives in urban areas and this share is expected to increase to $84 \%$ by 2050 [1]. The recently published European Commission White Paper includes

\footnotetext{
* Correspondence: kpapouts@gmail.com

${ }^{1}$ Department of Transport and Regional Economics, University of Antwerp, Prinsstraat 13, 2000 Antwerpen, Belgium

${ }^{2}$ Traffic, Transportation and Logistics Laboratory, University of Thessaly, Pedion Areos, 38334 Volos, Greece
}

\section{Springer Open}

(c) The Author(s). 2018 Open Access This article is distributed under the terms of the Creative Commons Attribution 4.0 International License (http://creativecommons.org/licenses/by/4.0/), which permits unrestricted use, distribution, and reproduction in any medium, provided you give appropriate credit to the original author(s) and the source, provide a link to the Creative Commons license, and indicate if changes were made. more competitive and sustainable transport system through the achievement of $\mathrm{CO}_{2}$-free city logistics in major urban centers by 2030 [2].

Urban freight transport serves wealth-generating activities like trade, industry, etc. [3]. It also ensures the supply of goods in stores and thus it is an important component for economic viability of the cities [4]. However, freight vehicles' movements burden the urban environment with additional road congestion and spatial constraints which serve as an impediment for the efficiency 
of freight operations and their level of service [5]. Apart from the aforementioned impacts, there are environmental implications (e.g., atmospheric emissions and noise), societal issues (e.g. accidents and quality of life), impacts on the economy and on the mobility (e.g. congestion resulting in decreasing urban accessibility) [6].

The configuration of urban freight transport systems has led to unsustainable levels of economic efficiency and livability [7]. Transportation has a strong influence on the environment, the economy and the society. The call for incorporating sustainability into urban planning is therefore imminent. There are many definitions of sustainability and sustainable development; the World Commission on Environment and Development [8] defined sustainable development as: "Development that meets the needs of the present without compromising the ability of future generations to meet their own needs". Sustainability checks can be applied to any system to describe the balance within this system. Initially, sustainability focused mainly on environmental issues, but thereafter, the range broadened and now includes economic and social issues.

A sustainable transportation system "allows the basic access needs of individuals to be met safely and in a manner consistent with human and ecosystem health, and with equity within and between generations, is affordable, operates efficiently, offers choice of transport mode, and supports a vibrant economy, limits emissions and waste within the planet's ability to absorb them, minimizes consumption of non-renewable resources, limits consumption of renewable resources to the sustainable yield level, reuses and recycles its components, and minimizes the use of land and the production of noise." [9].

Sustainability has been addressed extensively in transport due to the environmental, social and economic impacts that this sector has $[10,11]$. Jeon and Amekudzi [12] studied sustainability initiatives in North America, Europe and Oceania in the transport sector and beyond, highlighting their outcomes. Other attempts to deal with the sustainability assessment of transport operations have resulted in the development of frameworks like measures and indicators reflecting the sustainability components [9, 13-15]. Indicator frameworks have been developed that assess transportation impacts mostly on mobility, safety and environment. The sustainability assessment of freight transport systems is a complex process due to their multi-dimensional character. For instance, the sustainability assessment of the urban freight system requires taking into account all stakeholders involved [16]. Lee and Huang [17], argue that in order to determine whether a city is moving towards sustainable development, this can be achieved through the development of a sound assessment framework to ex-ante and ex-post assess the city's mobility capacity. Macharis and
Van Mierlo [16] highlight that amongst the most critical factors of sustainable urban mobility there are accessibility, economical welfare, health and safety, efficient use of space, natural resources and pollution prevention. As for assessment tools of the sustainability level in cities, a set of performance indicators represents an efficient assessment tool to properly evaluate measures and policies towards optimized urban planning [18]. Such tools could facilitate trend identification, policy rankings, evolution monitoring and future forecasting [19].

The main objective of this paper is to conduct a sustainability analysis of different urban retail logistics solutions which, practically, have been examined as innovative and traditional operational practices in the retail industry. This is achieved by the use of a simple, multi-dimensional framework incorporating the basic components of sustainability (economy, environment, society) together with an additional component that reflects the level of service. In order to estimate external costs, two factors are used: distance covered within cities and during the line-haul transport and a relevant external cost factor that reflects the local circumstances. The data in order to estimate the external cost impacts were retrieved in Delhaye et al. [20] and estimated in BorbonGalvez et al. [21]. The external cost outcomes that were estimated in Borbon-Galvez et al. [21] serve as the basic input for the analysis together with a set of urban retail logistics indicators that reflect societal impacts, handling and delivery costs, environmental burden and level of service. The results of the analysis bear witness of the complexity of retail logistics within an urban context and of the fact that sustainability of logistics, in terms of economic and environmental concerns, goes hand in hand with operational effectiveness and social uptake.

At first, the definition of sustainability is given and also the relationship with transport efficiency is established. A review of literature is also made with regards to the impact of urban policies and measures on the sustainability of retail logistics and also on evaluation techniques that are used in order to assess the sustainability of urban logistics operations. The main advantages and disadvantages of each retail logistics solution are identified together with the introduction of the retail logistics concepts. In addition, the background and the methodology of the analysis are described and the analysis itself, the results of which are discussed and based on which conclusions are drawn.

\section{Urban policies and their impact on the sustainability performance of the retail sector}

In the recent Top of Mind ranking of The Consumer Goods Forum (2011), corporate responsibility (including sustainability) was ranked as one of the most important company image influencing factors by retailers. Large 
retailers are the ones who often have a high level of control in supply chains, so they are in a position to implement sustainability standards in their supply chains [22,23].

Erol et al. [24] conducted an in-depth review of the existing literature on sustainability research in grocery retailing. Carter and Rogers [25] used conceptual theory building to develop a framework for sustainable supply chain management. Seuring and Muller [26] create a conceptual framework for sustainable supply chain management, focusing on developing two strategies. Brammer et al. [27] analyze how to manage international, sustainable supply chains using a systematic literature review. According to those authors, retail is the third most analyzed sector in the research on international sustainable supply chains. Finally, Carter and Easton [28] provide an overview of the recent literature on sustainable supply chain management. Quak and de Koster [29] consider social responsibility and environmental sustainability to a higher extent in their research. Moreover, even within a certain sustainability dimension, the research sometimes focuses on very specific aspects of that dimension. For instance, Thompson [30] mostly discusses energy savings as the principal pillar of environmental sustainability dimensions relevant to retailers [31]. Mitropoulos et al. [32, 33] perform a sustainability assessment of different types of vehicles for passenger and freight transport using Life-Cycle Analysis through a concrete indicator-based framework.

Urban freight policies and measures initiated both as publicly-oriented initiatives and as private operational models have a wide range of impacts in different areas. Papoutsis and Nathanail [34] recorded different urban freight solutions and their impacts on several sectors such as environment, society, economy and transport performance. Behrends et al. [35] addresses this complexity of the urban logistics context by providing an indicator-based framework which evaluates impact and performance of urban freight transport taking into account the variety of actors in the supply chain. Browne et al. [36] focus on night-time delivery restrictions. The results showcase considerable cost increases for retailers due to night-time restrictions, lower distribution costs and higher journey reliability. However, this had a negative impact on residents due to noise nuisance and light disturbance.

Public policies that address sustainability concerns could include the implementation of time-windows. Quak and de Koster [37] present the economic and environmental impact of time windows on different Dutch retail chains. It is generally observed that an increase in the length of a time-window results in a significant cost reduction for retailers and minimization of associated environmental impacts. Harmonization of the timewindows between municipalities could also assist the achievement of higher social uptake and better sustainability effects without unnecessarily impacting on the environment and the retailers' profit. In this regard, imposing a new time-window scheme or shrinking existing time-window usually causes an increase in retailers' distribution costs. Groothedde and Uil [38] assess vehicle size restrictions and find these restrictions to increase costs for Dutch retail significantly. Coordinated goods distribution systems have proven to indicate more efficient deliveries for retail and transport operators in terms of improved vehicle utilization, alleviated traffic conditions and a more eco-friendly culture of the delivery operations. There are many other literature sources where authors review implemented urban freight measures designed both as public policies and as logistics solutions of private operators [39-50].

The use of a distribution center in the city of Groningen results in more vehicle movements for the food retail leading to more environmental burden and less sustainable operations in environmental terms [51]. The total impact on economy and environment depends on the retailer's logistics concept. Retailers who bundle many deliveries in one trip may encounter higher impact than the retailers who include only a few deliveries in one trip [6].

In the next section, a Strengths-Weaknesses analysis of logistics solutions tailored for being applied in the urban retail context is developed. The section introduces the measures, the external costs of which are calculated in section 4 under the methodological approach. The external costs are calculated per urban policy and per urban logistics concept and the results feed the sustainability analysis that takes place in the subsequent chapters, shaping the indicator-based sustainability evaluation framework. The reason external costs are used as the core of our sustainability framework is because the logistics operations create a range of externalities causing impacts mainly on society (infrastructure damage, environmental pollution, mobility obstacles etc.) which urge people and, principally, authorities to allocate budget towards mitigating them. Eventually, the impacts of external costs are economic, environmental and overall social.

\section{Strengths-weaknesses analysis of retail logistics solutions applied in urban context}

In this section, a Strengths-Weaknesses (SW) analysis is conducted for three alternative retail logistics concepts. The pros and cons of the introduction of an urban consolidation center, the tethering concept and the shared bus initiative is described. It is assumed that all of them are introduced in order to improve the retail deliveries of FMCG. ${ }^{1}$

Below, each concept is briefly described before investigating its SW aspects: 


\subsection{Urban consolidation centre}

Urban consolidation centres (UCC) are constructed and operated with view to improving the performance of urban freight deliveries. The main idea of this initiative is to bundle goods stemming from different shippers and share capacity of both infrastructure (storage area) and vehicles. In parallel, more conducive regulatory frameworks are developed to ease cooperation of involved stakeholders. Expected outcomes of this kind of initiatives are the reduction of costs and truck-kilometres as well as mitigation of $\mathrm{CO}_{2}$ emissions and energy consumption [21].

Advantages of consolidation centers include the potential to achieve higher capacity (and resources) utilization because of the goods bundling and mitigating the driving time of delivery trucks in congested roads. The higher volume/weight utilization leads to the reduction of unit costs of transportation for the 'last-mile' distribution (economies of scale are achieved) [7]. Consequently, the number of vehicle kilometers is expected to be reduced, just like the number of freight vehicles in the network. The use of alternative modes of transport is promoted and is becoming more feasible i.e. indicating electric vehicles as the one that matches better to an urban context. Finally, constant checking of the consolidated cargo increases stock transparency.

However, there might be a lack of direct interface between shippers and customers, and suppliers would prefer to have a direct view of final consumers in order to measure and adjust their productivity and evaluate customer satisfaction [34]. Furthermore, cargo may have already been consolidated before reaching the urban consolidation center and thus, trying to channel cargo flows in the urban consolidation center may create inefficiencies regarding cargo consolidation. High initial investment and operational costs could serve as an impediment towards attracting stakeholders.

Public subsidies could be a step towards resolving such issues but even national governments need to be convinced on the effectiveness of supporting such initiatives. A potential lack of enforcement or regulations for vehicles may hamper the establishment of cooperative schemes. Also, plans of urban consolidation centers sometimes fail because there is a lack of ex-ante assessment. For small cities, operation of an urban consolidation center may result in boosting supply over local demand and, in turn, lead to under-performing of the operators. Similar issues arise when there is a monopoly. As far as large cities are concerned, the demand level may not be met especially in storage requirements. Finally, an erroneous location of the center may result in increasing costs of transportation. The number and type of involved stakeholders and the goods transported is also an issue that could determine whether the initiative is successful or not [7].

\subsection{Tethering scenario}

This innovation emerges from a situation when urban logistics schemes use large commercial vehicles while access restrictions allow only light commercial vehicles or electric vehicles to enter the urban area. The tethering would be an innovative opportunity to use retailers' large supermarkets in the outskirts of the urban areas, as fulfilment or replenishment centres for retailers' outlets in hardly accessible urban areas [21].

Tethering would allow retailers to face newly emerging access restriction schemes quite inexpensively (i.e. compared to setting up different delivery schemes), storing, assorting, handling, and/or cross-docking for the urban retail outlet at the retailers' supermarket facilities. This would then allow shifting cargo from large to light commercial vehicles, access urban areas and achieve reduction of lead times (i.e. compared to common business models), without substantial investments and thus, low final delivery costs and increased returns. Tethering provides full connectivity as the retailer's distribution system is fully connected from a supply chain perspective as well as a store associate and store assignment perspective. Moreover, customer satisfaction and company image might increase.

More opportunities are also being generated. Apart from the potential to reduce the cost base through shared functions between retail stores, from a supply chain perspective, leverage could be given to retail outlets (supercenters) to drive logistics savings. In addition, this new concept could promote e-commerce by enabling digital access to many more items offering the chance to pick them up or deliver them the same day [52]. Sales growth could also be increased as a result of the expanded assortment of goods [53].

However, from a distribution perspective, it is expected that for the small retail stores, the last mile would be very expensive for delivering a small number of pallets and the FMCG. This might necessitate a different approach; the retailers should diversify the way they treat different types of products: the fresh ones might need to be shipped directly to the retail outlet but, for example, the tethering scenario would be more beneficial for the dry products. Finally, for the slow-moving items, the existing delivery model would not change. The large retail outlets serving as supercenters could also act as mini-distribution centers that could not keep up with the volume of goods moving through the back rooms.

\subsection{Shared bus}

Another tested logistics opportunity is the use of the urban public transport systems for freight delivery. Previous analyses like the Mumbai box case and the mixed passenger and freight have described the convenience in terms of costs and capital investments [53, 54]. 
This model envisages the mixed transport of passengers and goods through the urban public transport system (public transport modes - buses). This implies an agreement between the retailer and the public transport management authority towards leasing the loading capacity of city buses [21]. Usually, the authority establishes cooperation agreements with more than one shipper so as to achieve economies of scale and achieve high load factors through efficient goods bundling. In our case, the cost model regards the retailer as the only partner of the authority. The unloading and loading of goods from the buses to the delivery vehicles - Masson et al. call them city freighters which could be electric vehicles/tricycles is performed by specialized personnel hired (or already employed) by the retailer. Finally, the vehicles that perform the last-mile distribution could be owned by the retailer - in this case, an increase is recorded in the initial investment costs - or leased by the retailer for the goods deliveries. The latter implies extra costs with regards to vehicle leasing and employing human resources (drivers). For simplicity, we assume that a retailer would opt for outsourcing the last-mile deliveries service instead of choosing further capital investments. The presence of a UDC ${ }^{2}$ owned by the retailer or retailer's large market outlets with ample space for logistics activities operating under the tethering model is required to facilitate goods bundling.

Tangible impacts of the introduction of such services could be the mitigation of total number of freight vehicle-kilometers and the concomitant mitigation of $\mathrm{CO}_{2}$ emissions. The utilization of buses could also be increased, offering maximum return on investment and create a new revenue stream for the public transport authority. If depots are used which will be preferably located outside the urban area, possibly near to the major motorways, then the service could be strengthened and the burden of the carriers could be relieved. Consequently, the environmental and social benefits would also increase. It should be also stressed out that local governments should foster such initiatives through targeted interventions and contribution that would allow for higher savings (in terms of arranging urban road traffic, removing regulatory constraints, etc.).

If this new measure is combined with the introduction of time windows, special attention should be paid to the level of service as shorter time windows may lead to increasing the number of last-mile operating vehicles and bus utilization. High upfront investment costs are needed in order to build or adjust transshipment spaces, hire personnel for goods handling both at bus terminals and at bus stops, etc. Social uptake should also be under investigation because the image of buses (and their level of service) is expected to change. Finally, there is an issue concerning the type of goods that should be transported (fragile, sensitive, etc.) and their size. Bus capacity is limited and its availability depends on several factors such as passenger demand, bus route and so on, and, thus, conflicts could be created between the retailer's demand and existing supply. Public transport is mainly a transport service for passengers and it should operate mostly with respect to passengers' needs.

Besides that, there are some side effects that might hamper the passenger service. Combining the freight and passenger service might lead to punctuality and reliability issues both for good delivery and for public transport service due to delays in goods unloading, lower speed, network differentiation, etc. This is because different range and types of drivers determines the public transport service compared to final goods delivery. A driving factor behind both services is cost, but for the goods delivery may be the most important while for passenger transport is one of the most important ones together with reliability, comfort, speed. Etc. As such, transport authorities aiming to satisfy the needs of their clients (who are passengers and private companies) might need to increase service prices, jeopardizing the potential benefits derived for the freight sector. Consequently, the value added of these mixed types of services might disappear. Further elaboration on this type of service is conducted by Trentini et al. $[55,56]$ indicating economic parameters as well.

\section{Methodological approach}

The cost effects of policy implementation should be integral part of the logistics cost structure of economic operators of the private sector. Public authorities design and implement policies to serve a variety of needs and goals set of public interest. When it comes to the urban environment, cities investigate different options of internalizing the transport externalities caused by the transport operations of the private sector as part of economic activity. Such policies can being additional costs to operators urging them to take investment actions or re-design their operations. For instance, policies like Low Emission Zones or alternative road charging mechanisms generate additional cost burden for operators. Inevitably, operators ought to incorporate these cost elements into their existing cost structure and to go after new service models to address these side effects and tackle, if possible. The logistics concepts described in the previous chapter comprise some of the many logistics measures that a shipper or a service provider can design and put in motion with view to optimize costefficiency of supply chains.

The methodological approach pursued in the paper implies the use of external costs of freight transport as the main drivers of sustainability performance. To this end, authors estimated external costs of transport and 
fed a sustainability-oriented framework consisting of a variety of indicators. The framework was developed to capture the sustainability performance of retail logistics demonstrated as economic, environmental, social and service impacts.

\subsection{External costs}

Externalities can be defined as changes in welfare caused by economic activities without these changes being reflected in market prices [57]. The most important external costs categories identified in the literature are accidents, noise, air pollution, climate change, infrastructure wear and tear and congestion $[58,59]$. The external costs generated by economic activities (i.e. transport) are closely associated with the sustainability concerns as described in the previous chapter. In fact, the lower the external costs are, the most sustainable the activity is. This is supported by the principle that there is lower negative economic impact and thus, fewer resources are needed to compensate for the loss.

The analysis of external costs takes into account six categories which are also mentioned by Ricardo-AEA [60]. The analysis made in [20] regards - among else - a cost estimation of the external costs produced by the logistics activities of an international food retailer operating also within the city of Antwerp. The retailer is a large known supermarket company that has many times led by example with regards to introduction of successful logistics solutions and owns a wide network of retail outlets especially within Belgium but also in the Southeast Asia, southern Europe, etc. The analysis is based on the assumption that retailer's DC is located around $50 \mathrm{~km}$ far from the Antwerp urban area. For the sake of the analysis, it was assumed that the trip starts when a truck is leaving the regional DC and ends after delivering the last pallet when the trailer gets empty. Therefore, trips back are not taken into account. The background set for the study implies the introduction of a $\mathrm{LEZ}^{3}$ in the city of Antwerp which has been implemented by February 2017, and a road charging policy that has already been introduced and impacts on transport costs of freight vehicles. To this end, we investigate the cost impacts of specific urban retail logistics concepts: the operation of an urban consolidation center, a tethering scenario of retail outlets and a shared buses scenario as solutions in order to tackle the cost impacts of the applied policies. The latter implies the use of public transport to ship the goods from the city outskirts close to a final drop-off point. The methodological approach followed in order to estimate the external costs generated by the delivery trips in the city of Antwerp and the line-haul transport (the distance between retailer's distribution center and the city of Antwerp) uses data which are recorded and adjusted.

Innovation is a track with broad application to the urban retail sector and relevant solutions are designed in order to mitigate the additional costs that might be generated to retailers through the introduction of new policies. The desirable outcome is that cost savings achieved offset the excessive costs that policy implementation brings out.

\subsubsection{Low emission zone}

In Antwerp, starting from February 2017, a Low Emission Zone (LEZ) policy has been introduced for vehicles not complying with Euro norm from 4 to 6 . Thus, a retail company that operates within the core city area has three options: adopting Euro 4-6 vehicles to be exempted from road charges, paying a higher road charge, or avoiding compliance and, thus, receive fines. The figure below indicates the area in which the LEZ constraints will be imposed (Table 1). The LEZ is a special geographical area where special charging schemes are applied for vehicles entering this area (Fig. 1). The aim of this policy is to mitigate the air pollution and environmental burden in special urban cores. Thus, only vehicles which are compliant with the regulation (usually modern ones or technologically advanced - cleaner) are allowed to enter this area.

\subsubsection{Road charging}

The administrative regions of Belgium have decided to reform the traffic tax. This implies that the use of a truck

Table 1 LEZ charges for the city of Antwerp

\begin{tabular}{|c|c|c|c|c|}
\hline $\ln €$ & Period & Normal tariff & Reduced tariff & Increased tariff \\
\hline \multirow{5}{*}{$\begin{array}{l}\text { N2 } \\
\text { Category } \\
\text { Light freight vehicles } \\
\text { Weight 3.5-12 ton }\end{array}$} & Day & 30 & & 35 \\
\hline & Week & 50 & 40 & 60 \\
\hline & Month & 130 & 70 & 160 \\
\hline & 3-Month & 350 & 180 & 440 \\
\hline & 6-Month & 700 & 360 & 870 \\
\hline \multicolumn{5}{|l|}{ N3 } \\
\hline $\begin{array}{l}\text { Lategory } \\
\text { Heavy freight vehicles } \\
\text { Weight }>12 \text { ton }\end{array}$ & Year & 1380 & 700 & 1730 \\
\hline
\end{tabular}

Source: [76] 


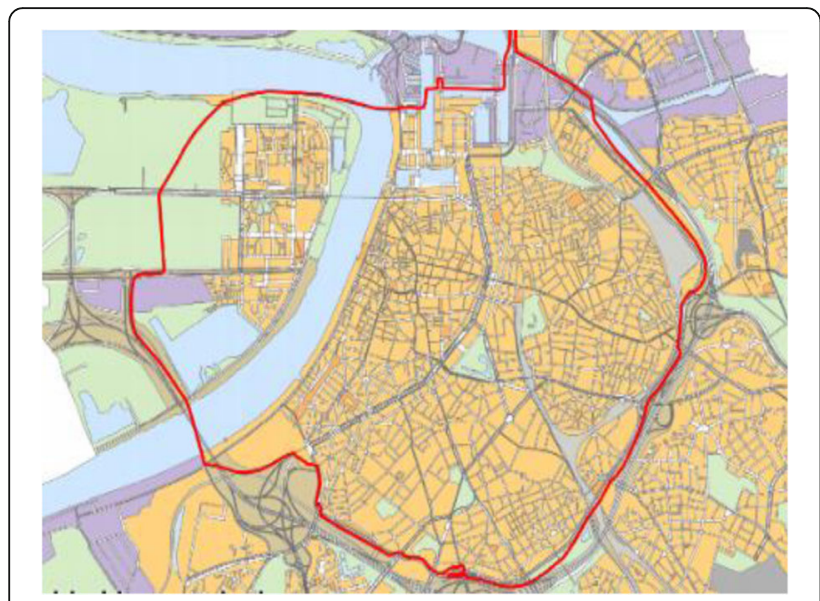

Fig. 1 LEZ area in the city of Antwerp [76]

will be imposed a tax instead of its ownership. So, in order to compensate for the external costs created by the use of such vehicles, a per kilometer charge of road transport has been introduced since April 2016 for Heavy Goods Vehicles of more than 3.5 tons Gross Vehicle Weight. In the picture below (Fig. 2) we can see the road links in the Belgian territory that are subject to road charging.

The rates (Table 2) have been fixed based on three parameters:

- The Gross Vehicle Weight: the kilometer charge is due for trucks of more than 3.5 tons of Gross Vehicle Weight.

- The Euro emission norm: this is the emission norm that categorizes the level of pollution of the truck (Euro 1-6).

- The type of toll road: all roads in Belgium are toll roads. Most of them are charged at zero-tariff.
Although the study [20] makes a reference to data from 2000 to 2008, a specific methodology was used in order to update the values. The logic relies on the approach $\mathrm{km}$ cost factor $\mathrm{x}$ kilometers covered. The local congestion factor is already incorporated in the cost factor illustrating local traffic conditions. This entails that the cost per kilometer is higher when the average level of congestion in and around Antwerp is also higher compared to other cities of same geography, spatial context, economic characteristics and demographics. The study refers to regional data input from traffic, environment, road infrastructure, noise generated by traffic congestion, visual implications, climate, and develops along different types of transport modes (freight heavy and light, passenger). For the sake of our analysis, we assume heavy trucks circulating in the regional road network and lighter ones for urban delivery. Adjustments have been conducted where possible to reflect the actual business-as-is.

- at first, the evolution of external costs per unit of measurement was identified in terms of \% increase/ decrease in the years 2000 to 2008.

- Then, an average value was generated indicating an annual rate of increase or decrease of the external cost impact between these years.

- It was assumed that for the years after 2008 and until 2014, the same trend is recorded and, after an extrapolation of values and an update of values to 2014, the external cost impact for the year 2014 was estimated. As the data collection process and analysis took place during the year 2016, it has not been able to incorporate validated data of the year 2015, exploiting, in turn, the latest and most reliable

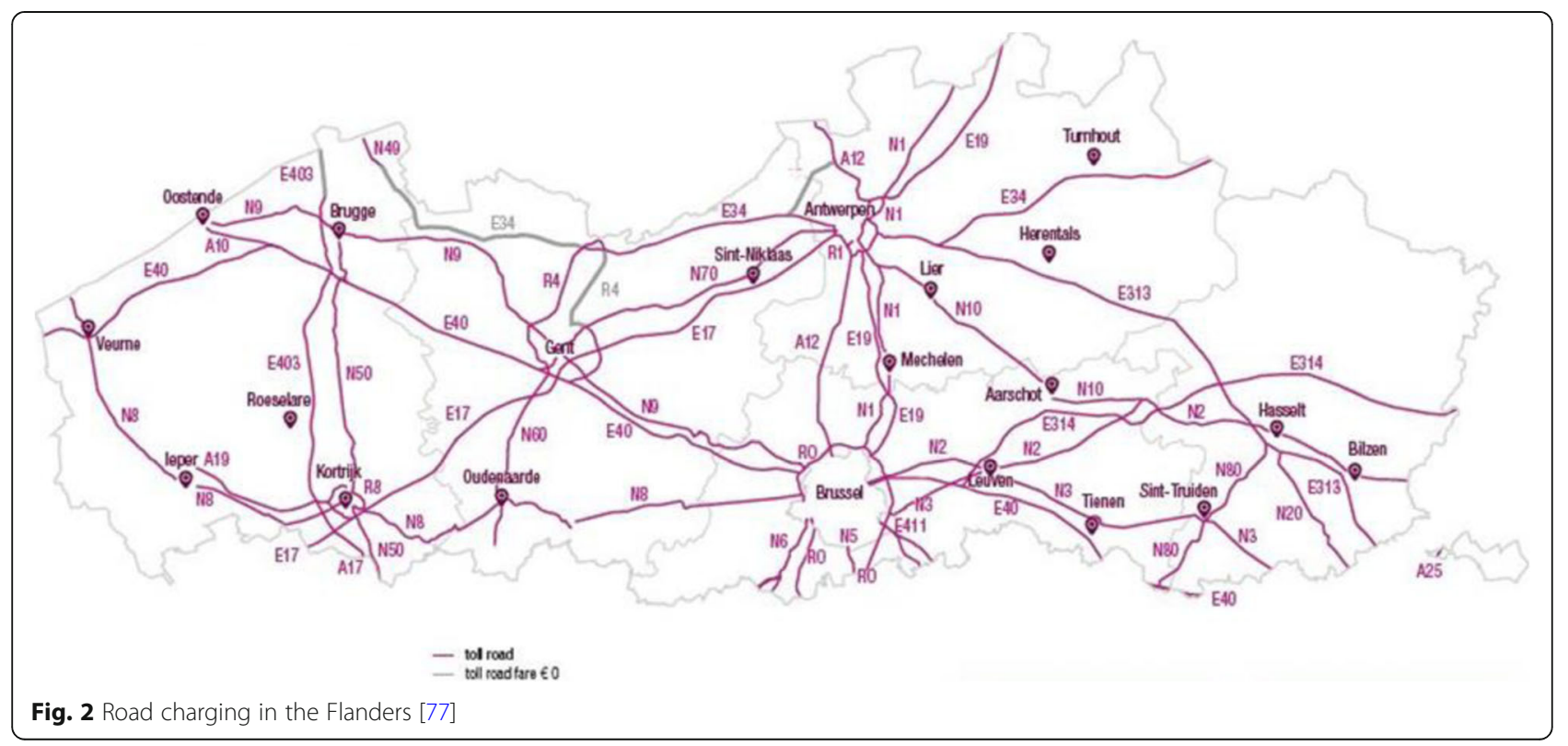


Table 2 Road charging rates in Belgium (€/km)

\begin{tabular}{|c|c|c|c|c|c|c|}
\hline & \multicolumn{3}{|c|}{ Flanders, Wallonia and Brussels Highway } & \multicolumn{3}{|c|}{ Brussels urban area } \\
\hline & $3.5-12$ tns & $12-32$ tns & $>32$ tons & $3.5-12$ tns & $12-32$ tns & $>32$ tons \\
\hline Euro 0 & 0.146 & 0.196 & 0.200 & 0.188 & 0.263 & 0.292 \\
\hline Euro 1 & 0.146 & 0.196 & 0.200 & 0.188 & 0.263 & 0.292 \\
\hline Euro 2 & 0.146 & 0.196 & 0.200 & 0.188 & 0.263 & 0.292 \\
\hline Euro 3 & 0.126 & 0.176 & 0.185 & 0.163 & 0.238 & 0.267 \\
\hline Euro 4 & 0.095 & 0.145 & 0.149 & 0.132 & 0.207 & 0.236 \\
\hline Euro 5 & 0.074 & 0.124 & 0.128 & 0.109 & 0.184 & 0.213 \\
\hline Euro 6 & 0.074 & 0.124 & 0.128 & 0.099 & 0.174 & 0.203 \\
\hline
\end{tabular}

Source: https://www.viapass.be [77]

data available (-2014). The outcome of this procedure was an updated cost factor per $\mathrm{km}$.

- Finally, in order to derive the final external costs for each category, the external costs per kilometer were multiplied by the number of kilometers covered in each logistics solution (scenario) both for line haul and urban transport. The amount of distance covered by trucks for each solution is based on the literature and on the retailer's estimations in accordance to the location of DCs, ${ }^{4}$ retail outlets and its operational model (year 2016).

The analysis involved both the line-haul transport (from regional distribution center to retail outlets) and urban context (delivery trip). It has also been performed for all different urban retail logistics initiatives and for the six external cost categories. The level of detail was the highest possible as different types of vehicles were taken into account for different urban networks (in geographical terms) and the analysis for air pollution included a breakdown of pollutants: $\mathrm{SO}_{2}, \mathrm{PM} 2,5, \mathrm{CO}_{2}$, $\mathrm{N}_{2} \mathrm{O}, \mathrm{CH}_{4}$, VOS, $\mathrm{NO}_{\mathrm{X}}$, etc. Data and results were also validated using relevant literature [61-66]. The external cost impacts of this analysis provide feedback on the sustainability analysis conducted in a next chapter.

External costs disrupt the market mechanism and, as such, one needs to pass on the external costs of transport to the user. The market economy lacks mechanisms to pass on such costs to the producer of transport services. The aim is to impose a charge that corresponds to the marginal external cost. Charges can be imposed in order to compensate for external costs. The level of this charging should be proportionate with the external costs. This idea is known as internalization of/charging for external costs. The main benefit of such levies to compensate for externalities is not necessarily financial. The purpose of these levies is not to finance new infrastructure investments but to be collected by the government and re-invested or used in several ways.

In order to capture the degree of internalization of (marginal) external costs by the policies that are implemented (LEZs and road charging) we compared the amount of external costs that are produced per trip (line-haul transport and urban area) with the revenues that are expected to be created through these two mechanisms. The method was based on the calculation of the total external costs per trip - stemming from the table above for BAU (Business-As-Usual) - and the total cost that would be incurred to retailers by the implementation of the policies (which is per trip). It is assumed that both the road pricing and the LEZ mechanisms aim exclusively at fully internalizing the costs of externalities created by the goods transport and the comparison is being made per trip. Figure 3 presents

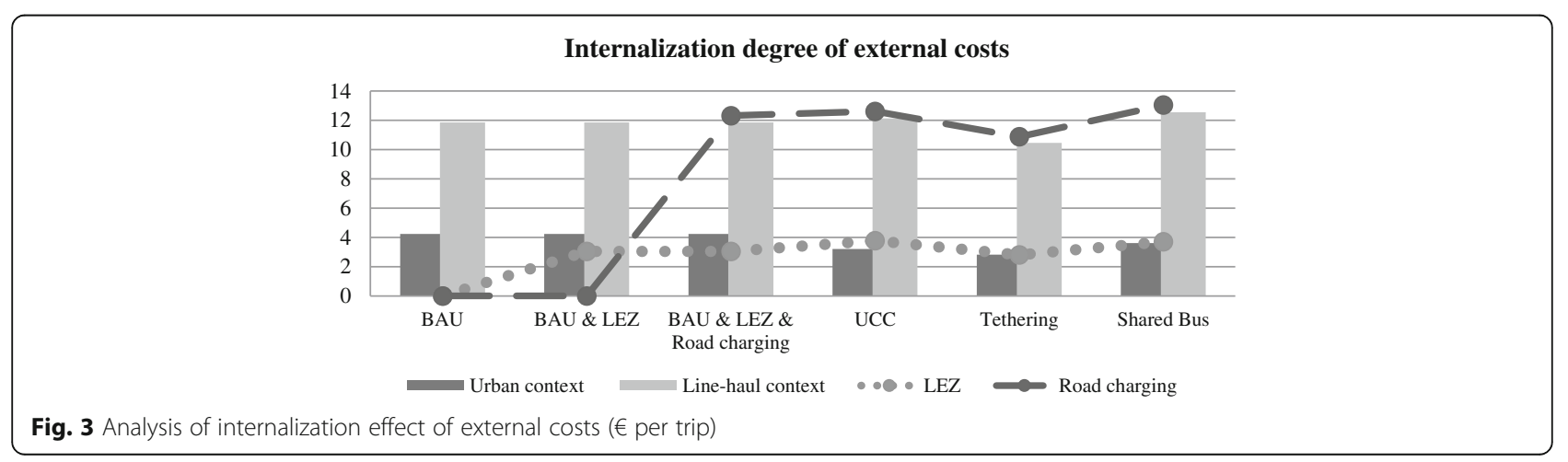


total external cost per trip (DC to urban delivery) which is estimated multiplying the cost per kilometre factor of external costs with the total (line-haul plus urban) distance covered. And this is estimated per different scenario (business as usual/BAU including policies/BAU including policies and logistics measures designed to offset additional costs).

The results indicate that:

- The logistics solutions that are promoted seem to have broader impact on the external costs generated in the urban leg of transport.

- The road pricing rate of the road charging policy applied to the line-haul transport are assessed as more effective as it outweighs the external costs generated under all scenarios.

- LEZ charges cannot offset the external costs generated within urban transport leg. In general, taking forward innovation that aims at mitigating external costs could assist corresponding revenues outweighing external costs.

- Higher compensation is achieved under the Shared bus scenario and lower is achieved under Tethering scenario.

- Tethering is assessed as the most sustainable scenario in terms of external costs produced (less vehicle-kms covered) so fewer charges are also imposed (as they reflect cost per km covered).

\subsection{Sustainability framework and analysis}

In order to develop the sustainability framework for the assessment of logistics solutions initiated by retailers operating within an urban context, we use sustainability as an overall context that contains three pillars: economy, environment and society [34]. Another fourth pillar is added: transport, which depicts the principle of introducing sustainability in retail operations without sacrificing effectiveness and high level of service. The pillar 'Transport' has also impact on the other pillars: for example high congestion level implies higher delivery costs, higher level of pollution in urban areas and less attractiveness of the urban environment.. In the case under analysis, the distance-oriented indicators were used to calculate the external costs. In general, the other indicators that we use are not correlated with distanceoriented indicators or external cost indicators. This could be explained by the fact that there are common grounds between the social and environmental dimension as well as by the fact that transport generates external and internal costs; As such, it is difficult to fully avoid overlapping in similar cases. However, in order to estimate sustainability performance, a lot of diverse factors are co-factored and, thus, the final scores are differentiated.
Pillar 1: Economy - The economy portrays the evaluation of an initiative with respect to economic resources (investment and operational costs) used to put forward this initiative and reflects its financial effectiveness. However, there is a linkage between the economy and the sustainability pillars. An unsustainable economy leads to the environmental deterioration and affects society usually disproportionally.

The indicators used under the category Economy are: handling costs and Value of Time costs. The latter was calculated using two components, the value of freight time (which was equal for all four different alternatives as the type of goods does not change) and the delivery trip time. All values that are used were derived from [20].

Pillar 2: Environment It includes a wide range of components, many of them falling also under the umbrella of economy, such as external costs, and its categories: air pollution, climate change, noise nuisance, etc. It is one of the most over-arching principles of sustainability as one of the most related sustainability criteria for the assessment of urban retail logistics.

For our analysis, we used $\mathrm{NO}_{\mathrm{x}}, \mathrm{SO}_{2}, \mathrm{PM} 2,5$ air pollutants combined with $\mathrm{CO}_{2}$ emissions, climate change and noise nuisance costs as estimated by [20].

Pillar 3: Society - When it comes to social concerns, the sustainability check regards assessing the uptake and acceptability of a solution and its effects on how people perceive the urban environment in terms of attractiveness of natural landscape, business opportunities and the quality of life in general. Sometimes, social factors are also considered the ones that have to do with road safety and visual intrusion caused by traffic or infrastructure damage.

The indicators that are used in our analysis regard part of the external costs estimated by [20] (Fig. 3, Table 3), such as infrastructure damage costs, accident costs and congestion costs. Most of them could also be deemed as environment-related costs, but for our case study it was decided that they should be treated under a social perspective because of the strong impact of these external cost categories on local communities. One could also address air pollution costs in a similar way. Additionally, the indicators "attractiveness of urban environment" and "space occupancy" are incorporated in the analysis. The former represents the extent to which a new measure is socially acceptable in terms of visual intrusion, physical nuisance, accessibility and other dimensions that fall under the umbrella of urban livability. The latter investigates to what degree the visual disturbance and the lack of accessibility that are perceived when expanding logistical operations taking place in urban areas affect the social take-up of new policies or measures.

The data used in the two last-mentioned two social indicators were derived by numerous researches [56, 67-75]. 
Table 3 External cost impacts per retail logistics solution and category of external costs (urban context) (in €)

\begin{tabular}{llllll}
\hline & & Business as-is & UCC & Tethering & Shared bus \\
\hline External costs & Accidents & 0.516 & 0.560 & 0.490 & 0.630 \\
& Air pollution & 0.486 & 0.304 & 0.266 & 0.342 \\
Climate change & 0.030 & 0.032 & 0.028 & 0.036 \\
Congestion & 1.823 & 0.960 & 0.392 & 0.080 \\
& Infrastructure & 0.516 & 0.448 & 0.797 & 1.025 \\
\hline
\end{tabular}

Source: own elaboration based on [20]

Pillar 4: Transport - This pillar regards the assessment of the performance of the transport and logistics operations without penalizing the sustainability of operations. Key success points are: efficiency and reliability of urban freight transport.

Transport efficiency and reliability are evaluated using distance based performance indicators for the urban context and (relevant) punctuality of deliveries are variables that are used. Data were retrieved from other sources [20, 40, 56, 68-73].

Apart from the literature sources used to validate the indicator values, some of them were also validated by retail supply chain manager during the interviews.

For each one of the aforementioned sustainability pillars, a set of assessment indicators is used that reflect the context of each pillar. The indicator-based framework is used to assess the alternatives which, in our case, are the urban retail logistics concepts. Then each indicator is evaluated according to each alternative.

Table 3 below presents the quantified sustainability indicators for different urban retail logistics concepts. The sustainability indicators are firstly separated into indicators that have positive (+) impact, and indicators that have negative (-) impact. Since indicators are expressed in different units, the aggregation of indicators into a single sustainability category index per retail logistics concept can be done by normalizing the value of each indicator for each concept and by using eqs. 1 and 2 and then comparing the normalized values by assigning weights [74].

$$
\begin{aligned}
& N_{i j}^{+}=\frac{I_{i j}^{+}-I_{\text {min }, j}^{+}}{I_{\text {max }, j}^{+}-I_{\text {min }, j}^{+}} \\
& N_{i j}^{-}=\frac{I_{\text {min }, j}^{-}-I_{i j}^{-}}{I_{\text {min }, j}^{-}-I_{\text {max }, j}^{-}}
\end{aligned}
$$

$N_{i j}^{+}$is the normalized indicator with positive impact achieved by the ith alternative concept with respect to the jth indicator. $I_{i j}^{+}$is the indicator value scored by the ith alternative concept which is evaluated according to the jth indicator, $I_{\text {min,j }}^{+}$is the indicator that indicates the worst value (lowest when the indicator has positive impact) achieved by the jth indicator and $I_{\text {max,j }}^{+}$is the optimum (highest when positive impact) value of $\mathrm{jth}$ indicator. Finally, as far as $N_{i j}^{-}$is concerned, for instance, $I_{\text {min }, j}^{-}$is the indicator which refers to the highest absolute value of a specific sustainability indicator between the alternative concepts, namely the highest negative impact.

The normalized values are dimensionless and range from 0 to 1 . As such, therefore the greater the absolute value of the normalized indicator, the more sustainable it is considered. Indicatively, the most sustainable vector for each concept is $I_{\max }=(1, \ldots 1)$ and the least sustainable vector is $I_{\text {min }}=(0, \ldots 0)$ where its components are equal to the number of the sustainability categories (i.e. environment, economy, etc.).

In order to aggregate the normalized indicators for each sustainability category and to estimate the overall sustainability score per each alternative concept, we use the weighted sum method (WSM) [75].

The value of alternative $A_{i}$ and its assigned weight $w_{j}$ for each indicator $\mathrm{j}$ is expressed mathematically as:

$$
V_{i}=\sum_{j=1}^{n} w_{j} N_{i j} \text { for } i=1, \ldots, m
$$

In this analysis we assigned equal weights to each indicator into a sustainability category and each of these sustainability categories is assigned the same weight $(0,25$ for each one of the four pillars)..

The paper provides room for wider application of weighted approaches. In general, weights reflect the stakeholders' and decision-makers' preference. This applies more when different stakeholders are actively involved with conflicting interests so each different stakeholder group comes with a specific varying weight forming potentially part of a sensitivity analysis. Drawing the red line around paper's scope, this paper is structured addressing retailers' interest and operations focusing on service and economic effects on their profile and partly on local communities. Economic and service indicators illustrate solely the retailers' interests. On the other hand, social and other environmental impacts affect society to a greater extent. We assume that the logistics solutions used as scenarios call for private investments; Moreover, policy 
implementation impacts private operators' cost structures and externalities are estimated based on the number of kilometers driven by retailer's fleet. In that regard, the paper retains a single-stakeholder point of view where the decision-making (i.e. which solution is more sustainable?) concerns private sector as the only investor group. However, some input for the social indicators has been already part of weighted analysis (i.e. attractiveness of the urban environment and space occupancy).

\section{Sustainability check and discussion of results}

The principal scope of this analysis was to indicate that sustainability is a multi-dimensional and broad concept. In urban retail logistics, which is considered a quite intensive economic activity, a variety of stakeholders are involved usually with conflicting interests and, thus, totally different perspectives and goals. As such, the introduction of both innovative and tested solutions into the urban retail industry may create unexpected outcomes, far from considered sustainable. To this end, there are a lot of tools and techniques that facilitate a sound evaluation of policies (policy-makers) or solutions (mainly private sector) and enable inclusion of many different factors into the single evaluation mechanism. Examples of such mechanisms are Cost-Benefit Analysis, Business Model Analysis, Multi-Criteria Analysis, cost analyses, etc.

For the sustainability category 'environment', the urban retail logistics concept that reaches the highest score is Tethering. This category consists of external cost components where the level of sustainability is proportional to the total distance covered. To this end, one could assume that the less the distance, the more sustainable the concept is. That is true if the approach already incorporates the effect of traffic congestion into the external costs factor. According to a relevant scale that is used in our case, Tethering scores the optimum 1, whereas the shared buses scenario scores 0 . This is due to the fact that for all sustainability indicators, the values reached by the Tethering scenario are the most positive ones, as the external cost indicators present a negative (-) impact. On the contrary, the shared bus concept scores the weakest, namely it shows the highest external costs between all alternatives. The UCC and the business-as-is concepts score relatively good results.

For the sustainability category 'society', the tethering scenario is again the most favorable one. That is because the interventions needed to be taken forward for this concept (expanding the storage area of already existing retail outlets, acquisition of more handling equipment and hiring employees in these retail outlets) present the lowest possible social disturbance. In addition, the construction of a UCC or the use of existing infrastructure as a UCC would change the level of urban livability in a local context and, thus, would be challenging to achieve social uptake. Furthermore, the shared bus concept would change the image of the road network of the city as many new transshipment locations would be introduced along the network and delays could be observed in some bus routes due to the increased handling time of transported goods. From a social perspective, the existing operational model of the food retailer is positively evaluated; this could be explained as people are always concerned about any potential negative changes that new policies may bring to their level of livability.

As far as 'economy' is concerned, the internal costs (out-of-pocket costs) were investigated. Two indicators were used: handling costs and Value-of-Time (VoT) costs; the latter cost category is related to the type of goods (degree of decay) and the total transport time starting from the regional distribution center. Although the shortest handling time - and costs - are noted for the business-asis scenario, the introduction of a UCC is assessed as the most sustainable cost-efficient alternative concept. Despite the additional handling resources that are needed, the cost-efficiency level could be very high if the initiative attracted a lot of attention, many stakeholders were involved and if there was an effective roll-out of this new model. This could lead to impressive cost savings which actually constitutes an assumption for this case study. Tethering is also assessed very positively as an economically sustainable concept. That is because the transport costs (as part of the logistics costs) are the ones which are mostly affected by transport decisions [40].

Finally, 'transport' as a sustainability category implies that apart from the efforts to achieve more environmentfriendly and cost-efficient operations, the operational effectiveness and the level of service should also be sustained. The tethering scenario appears to be the most effective one; that is because the existing level of service would be less influenced by the change in the delivery model. It is estimated that the less effective would be the shared bus scenario: changing the itineraries of the distribution fleet, introducing new logistics spaces around the city context and using the public transport network for delivering special types of goods like FMCG could lead to more time frictions, more delays, higher distances to be covered and, in general, less seamless goods flows within urban networks.

Incorporating the partial outcomes for each sustainability category, we draw the conclusion that, given the indicators used and the assumptions taken, the most sustainable retail logistics concept that is applied in an urban context is the Tethering scenario (almost 90\%). The business-as-usual and the UCC concepts indicate almost equal sustainability scores and the less sustainable alternative is the shared bus scenario which scores around $10 \%$.

In order to achieve a more clear view of the results and to make a cross-comparison between urban retail logistics solutions and sustainability categories, Fig. 4 presents a schematic overview of the sustainability check. 


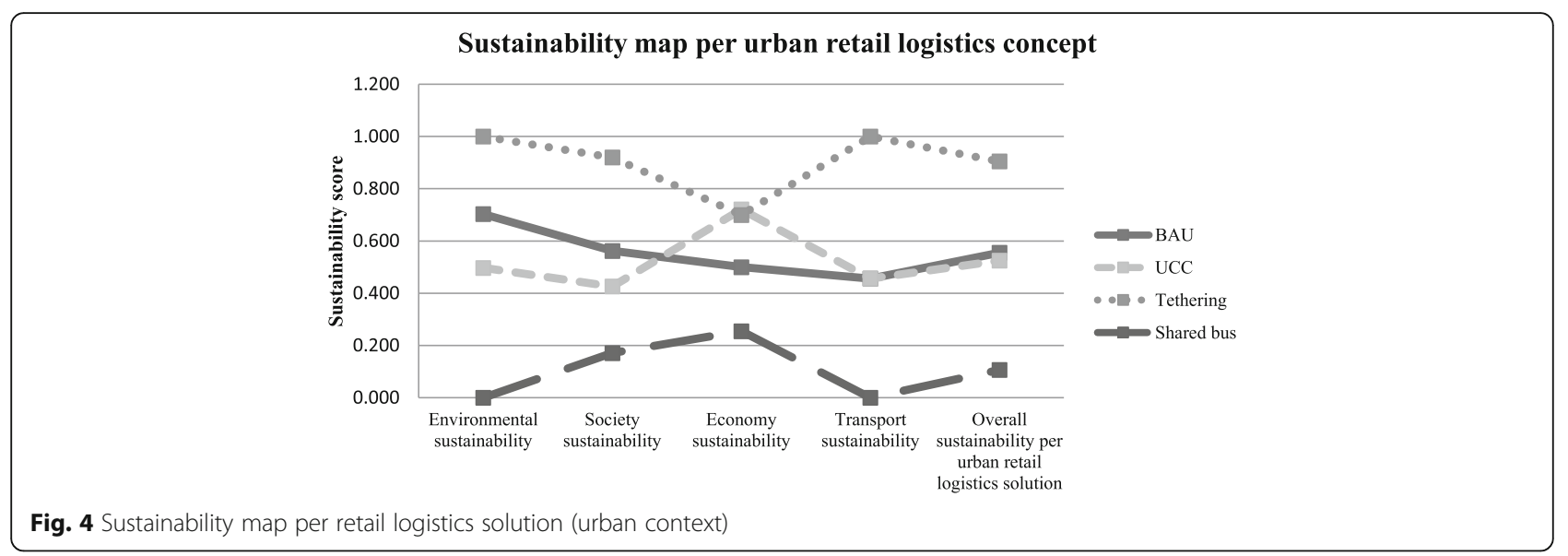

Drawing fruitful conclusions require addressing the results of this analysis under a holistic sustainability prism. The outcomes indicated tethering scenario as the most sustainable one, as it implies the lowest degree of interventions scoring a minimum impact on social and economic aspects. However, the input of our analysis was based on data from local transport and traffic circumstances. This is more obvious under the external costs indicators. The calculation of external costs requires local data collection; the kilometer factor that is used here stems from local traffic conditions, vehicle characteristics, etc. So there is no room for generalization of results. Furthermore, the analysis reflects business constraints: the business sector and its particularities are cofactored into this analysis impeding further results generalization. In particular, and taking as an example the most sustainable scenario 'Tethering', anticipates the use of a large retail outlet as a small DC in order to shrink the lead times. The structural interventions that are needed for the tethering option and are integrated into our analysis are based on the data that the retailer has provided and are intertwined with its operations in Antwerp. In a different case and location, interventions could be even more broad/limited resulting in different outcomes and impact on sustainability.

Another factor that affects the analysis' results is the business case itself: the number of kilometers that the delivery fleet covers within the city, the critical mass of products that is consolidated in the UCC which impacts on the load factor and, in turn, impacts on the number of trips, the part of transport that is carried out by public transport means under the shared Bus scenario, etc. There is a variety of criteria that exist in our case and define the red line; beyond that line, no generalization can be safely achieved. Table 4 presents each sustainability category index and the overall sustainability index per alternative scenario.

\section{Conclusion}

Urban freight systems represent areas with intensive economic activities that create externalities and adverse impacts on the urban environment. These externalities require mechanisms to internalize them and especially to the groups that create them in order to mitigate market disruption. The generation of external costs of accidents, air pollution, infrastructure damage, health issues as a result of noise nuisance, etc., shapes an unsustainable context where additional resources are needed to offset market imbalances. As such, a shift towards the reduction of external costs fosters sustainability.

Urban retail supply chains are considered a generator of externalities and attempts are made to incorporate sustainability into decision-making in the retail industry. That is because of the multi-dimensional nature of the retail sector, the volatile demand patterns, the just-intime requirements and the type of retail goods. Yet, more light has been shed on the logistics performance of the urban retail distribution than on the side effects that are produced in an attempt to maintain a high level of service. Different operational models and cooperative schemes with a view to achieving efficiency in deliveries produce different magnitudes of externalities. In this paper, a sustainability check has been made between alternative concepts of logistics solutions that are applied in the urban retail sector incorporating externalities into the impact assessment.

Concerning the external costs part of this research, the most sustainable initiative is the one which minimizes the product $€ / \mathrm{km} \times$ number of kilometers. That is because the factor $€ / \mathrm{km}$ depends on the types of vehicles: two types are used in our analysis, a truck for the linehaul transport and a lighter vehicle $(5 \mathrm{t})$ for the urban area under the different scenarios examined, leaving apart the BAU. For all different scenarios, i.e. BAU, UCC, tethering and shared bus, we use a single cost 


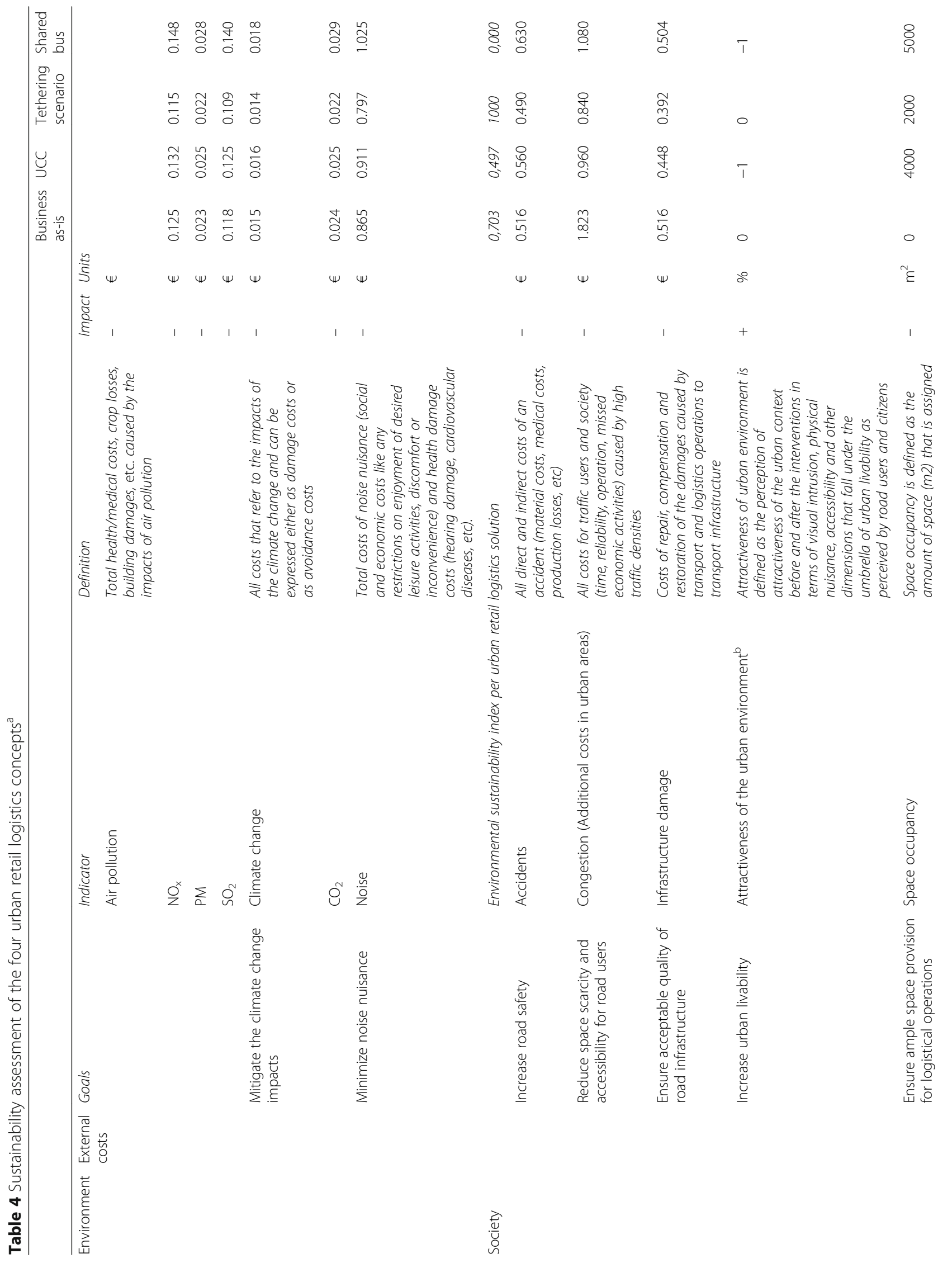




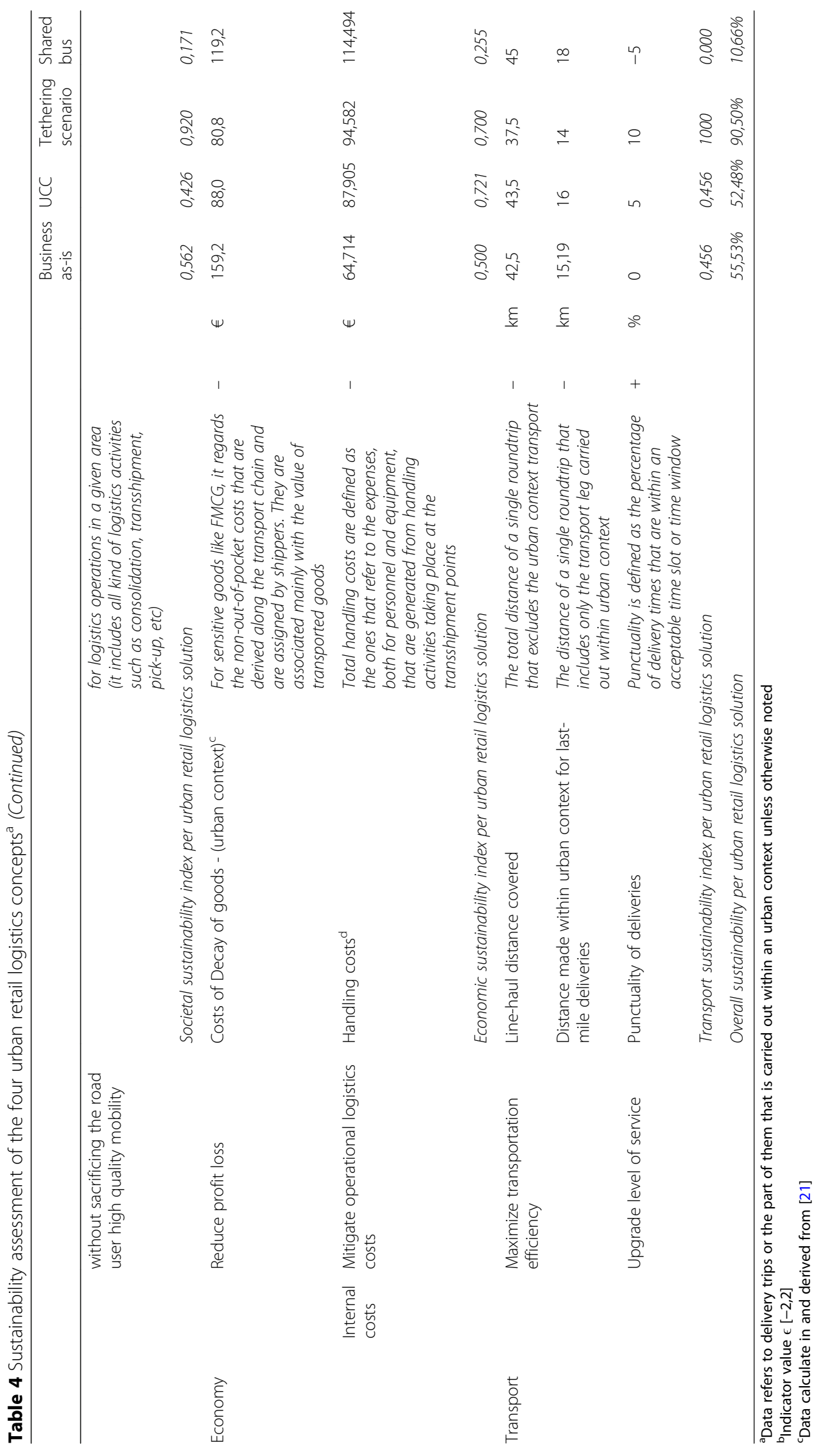


factor for the line-haul transport. The same approach is pursued for the urban transport leg where we use a different but fixed cost factor for these scenarios. In our case, and as the cost factor does not change, the tethering scenario is the one of which the transport leg showcases the shortest distance covered. Coincidentally or not, the most sustainable alternative, taking into account all the sustainability perspectives, is tethering; this proves that in a wider context, economic sustainability under a broader perspective - and reduction of externalities can go hand-in-hand.

The results are indicative of the assumptions made and the context in which the study has been developed. However, as the public policies and the scenarios represent already tested measures with a wider applicability, the outcomes of this research can be easily generalized. UCC is a tested initiative sourcing back in 1970s. On the other side, shared bus and tethering are quite fresh ideas in the retail sector and their implementation has started back in the 2000's and 2010's, respectively. In this regard, the input, assumptions and results have yet to be validated. Their capacity in terms of logistics performance and environmental alleviation relies also on the way they are deployed by the different retailers as many of these initiatives are in their testing period, and the urban contexts which accommodate them.

The urban consolidation center as a solution would not be so attractive for potential stakeholders unless its funding, for a significant period of time, is ensured. Also, an issue of utmost importance is the fact that a critical number of participating stakeholders should be attracted, as well a critical mass of goods and a specific type of them so as to tap full potential of the joint capacity, as anticipated. The economies of scale achieved would then increase its sustainability mainly in terms of economy, environment and transport service. 'Shared bus' is an ambitious idea but in our analysis, it achieved the lowest sustainability scores. In fact, mixing transport networks, introducing new logistics and transshipment spaces in the city, and the available capacity of buses are three factors that could determine the transport service, the social uptake and the economic performance of the initiative. The latter because it impacts the level of public transport service. The capacity of public buses to accommodate the different types of goods transported in the retail sector, and especially fast-moving goods, or sometimes large-sized items generates further doubts on whether this is the right solution for the retail sector. Maybe a good alternative that it is worth looking into is delivering parcels instead of europallets using the public transport.

Another key conclusion that is drawn through this analysis is that it is very challenging to attend sustainability in the retail sector, and especially for the urban areas. That is because the type of goods (usually sensitive, FMCG, etc.), the loading units and their size and the supplier-customer set up of the retail sector require highly responsive delivery models, closer to the just-intime principle. However, in order to serve these needs, and especially when introducing new delivery models for even quicker response imply increased number of vehicle movements, lower loading factors and, thus, less sustainable outcome. In this regard, smarter solutions are expected and innovation plays an important role in this sector due to the nature of the common structure of the retail delivery model. Instead, sectors that indicate different structure of delivery models (due to different types of goods, levels of demand, number of drop-off points, organization of deliveries, etc.) like Ho.Re.Ca or health care or parcel delivery may allow a more efficient allocation of resources in order to achieve sustainability. As a result of our analysis, the most sustainable initiative is the one that calls for the most efficient and the lower intervention so as to be implemented.

Struggling for achieving sustainable retail operations in the cities is also another critical issue for retailers. Sustainability per se, includes areas that are not of utmost importance for the retail companies. For instance, these could be external costs, 'social' impacts on local communities, air pollution, etc. As corporate responsibility emerges more and more retailers become interested on efficient utilization of their resources, and thus, mitigating externalities. Public policy holds a very important role; by the time that 'polluter-pays' principle is legally and broadly imposed, operators would be compelled to fundamentally reconsider the level of sustainability in their operations. And this because they might be legally forced to reduce the environmental footprint of their operations in order to cope with new costs. In general, sustainability culture in the retail sector could be promoted mainly through the introduction - in the form of regulatory or legal frameworks - of tailored mechanisms that aim at internalizing the externalities produced by retailers.

The internalization of externalities is a complex issue that requires reasonable road pricing policies and effectively organized mechanisms (i.e. police enforcement) in order to mitigate tax evasion (for road charging or LEZ charges) or fraud. Based on the results of our analysis, we could draw a conclusion that within urban areas it is difficult to achieve the foreseen level of revenues because of the multidimensional nature of the drivers that generate externalities. Congestion, air pollution and noise nuisance depend on the time of day, any unexpected incidents taking place in road network, policy implementation, etc. However, surveillance and enforcement could be more efficiently promoted. With regards to the regional 
transport, although the level of traffic could be more effectively anticipated, surveillance is more difficult due to the dispersion of traffic and the expansion of the road network. The enforcement actions should be accompanied with awareness campaigns in order to properly disseminate the usefulness of those measures to drivers. Finally, the road pricing policies and the mechanisms towards the collection of taxes/charges should be fair and transparent so as to achieve the highest possible social uptake.

The outcomes of this research could also provide feedback to future research agendas; this framework could be further deployed using additional criteria, indicators and perspectives; a life-cycle consideration could incorporate indicators and measurements from different time frames: operational phase of a measure, manufacturing/construction phase of assets and technological equipment, disposal, etc. As long as there are measurements and indicators, one could gauge the performance of a set of alternatives in order to back decision-making. Looking forward, other key challenges could emerge such as how to make specific types of urban supply chains, i.e. e-commerce, Ho.Re.Ca, waste management, etc., more efficient and resilient without jeopardizing their 'green' profile.

\section{Endnotes}

${ }^{1}$ Fast-moving consumer goods

${ }^{2}$ Urban Distribution Centre

${ }^{3}$ Low Emission Zone

${ }^{4}$ Distribution Centres

\section{Acknowledgements}

This research is part of project 140433 "Vlaams Onderzoeksproject Stedelijke Logistiek en Mobiliteit" supported by the Flemish Government programmes: 'Richting morgen, 'Vlaanderen in Actie', Vlaanderen is innovatie' and 'Pact 2020',

\section{Authors' contributions}

All authors read and approved the final manuscript.

\section{Competing interests}

The authors declare that they have no competing interests.

\section{Publisher's Note}

Springer Nature remains neutral with regard to jurisdictional claims in published maps and institutional affiliations.

Received: 19 August 2016 Accepted: 6 May 2018

Published online: 12 July 2018

\section{References}

1. United Nations (2012) World urbanization prospects, the 2011 revision. United Nations

2. European Commission (2011) Roadmap to a single European transport area - towards a competitive and resource efficient transport system. White paper, Brussels

3. Anderson S, Allen J, Browne M (2005) Urban logistics-how can it meet policy makers' sustainability objectives? J Transp Geogr 13:71-81

4. Crainic TG, Ricciardi N, Storchi G (2004) Advanced freight transportation systems for congested urban areas. Trans Res Part C 12:119-137
5. Hesse M, Rodrigue JP (2004) The transport geography of logistics and freight distribution. J Transp Geogr 12:171-184

6. Quak H (2007) Sustainability of urban freight transport - retail distribution and local regulations in cities. Erasmus Research Institute of Management (ERIM). Erasmus University, Rotterdam PhD

7. Nathanail E, Papoutsis K (2013) Towards a sustainable urban freight transport and urban distribution. J Traf Logis Eng 1:58-63

8. World Commission on Environment and Development (1987) Our Common Future. Oxford University Press, Oxford

9. CST - Center for Sustainable Transportation Sustainable Transportation (2002). Performance indicators

10. Macharis C, Melo S, Woxenius J, Van Lier T (2014) Sustainable logistics. Emerald Group Publishing. https://cris.vub.be/en/publications/sustainablelogistics(c806f087-caeb-4fcc-aac0-401c84cffda8).html.

11. Melo S, Baptista P (2017) Evaluating the impacts of using cargo cycles on urban logistics: integrating traffic, environmental and operational boundaries. Eur Transp Res Rev 9:30

12. Jeon CM, Amekudzi (2005) Assessing sustainability in transportation systems: definitions, indicators and metrics. J Infrastruct Syst 11:31-50

13. Nichols JE, Garrick NW, Atkinson-Palombo C (2009) A framework for developing indicators of sustainability for transportation planning. In: Proceedings of the 2009 Transportation Research Board annual conference, Washington D.C

14. Maoh H, Kanaroglou P (2009) A tool for evaluating urban sustainability via integrated transportation and land use simulation models. Urban Environ 3:28-46

15. Jeon CM, Amekudzi A, Guensler R (2008) Sustainability assessment at the transportation planning level: performances and measures and indexes. Transportation Research Board Annual Conference, January 13-17, Washington D.C

16. Macharis C, Van Mierlo J (2013) Sustainable mobility and logistics. VUBPress, Brussels

17. Lee YJ, Huang CM (2007) Sustainability index for Taipei. Environ Impact Assess Rev 27:505-521

18. Zito P, Salvo G (2011) Toward an urban transport sustainability index: an European comparison. Eur Transp Res Rev 4:179-195

19. Hermans E (2009) A methodology for developing a composite road safety performance index for cross-country comparison. PhD thesis. Hasselt University. https:/uhdspace.uhasselt.be/dspace/bitstream/1942/10232/1/PhD_ ElkeHermans_DIGITAL.pdf.

20. Delhaye E, De Ceuster G, Maerivoet S (2012) Internalisering van externe kosten van transport in Vlaanderen. Study for Vlaamse Milieumaatschappij. MIRA, Transport \& Mobility Leuven. http://www.tmleuven.be/project/ miraexternekosten/201010_finaalrapport_VMM.pdf.

21. Borbon-Galvez Y, Papoutsis K, Dewulf W, Vanelslander T (2016) A cost simulation instrument of urban policies on retail logistics. World Conference on Transport Research 2016, 10-15 July, Shanghai, China

22. Hingley MK (2005) Power imbalanced relationships: cases from UK fresh food supply. Int J Retail Distrib Manag 33:551-569

23. Brammer S, Hoejmose S, Millington A, (2011 b) Managing sustainable global supply chains, a systematic review of the body of knowledge

24. Erol I, Cakar N, Erel D, Sari R (2009) Sustainability in the Turkish retailing industry. Sustain Dev 17:49-67

25. Carter CR, Rogers DS (2008) A framework of sustainable supply chain management: moving toward new theory. Int J Phys Distrib Logis Manag 3895:360-387

26. Seuring S, Muller M (2008) From a literature review to a conceptual framework for sustainable supply chain management. J Clean Prod 16:1699-1710

27. Brammer S, Hoejmose S, Millington A, (2011a) Managing sustainable global supply chains - framework and best practices

28. Carter CR, Easton PL (2011) Sustainable supply chain management: evolution and future directions. Int J Phys Distrib Logis Manag 41:46-62

29. Quak HJ, De Koster MBM (2007) Exploring retailers' sensitivity to local sustainability policies. J Oper Manag 25:1103-1122

30. Thompson B (2007) Green retail: retailer strategies for surviving the sustainability storm. J Ret Leis Proper 6:281-286

31. Wiese A, Kellner J, Lietke B, Toporowski W, Zielke S (2012) Sustainability in retailing - a summative content analysis. Int J Retail Distrib Manag 40:318-335

32. Mitropoulos KL, Prevedouros DP, Nathanail EG (2010) Assessing sustainability for urban transportation modes: conceptual framework. Transportation Research Board Annual Conference. January 10-14, Washington D.C 
33. Mitropoulos LK, Prevedouros PD, Nathanail EG (2011) Sustainability framework: a case study of urban transportation vehicles. XXIVth World Road Congress, September 2011, Mexico city

34. Papoutsis K, Nathanail E (2016) Facilitating the selection of city logistics measures through a concrete measures' package: a generic approach. Trans Res Procedia 12:679-691

35. Behrends S (2011) Urban freight transport sustainability: the interaction of urban freight and intermodal transport. Chalmers University of Technology, Sweden

36. Browne M, Allen J, Anderson S, Woodburn A (2006) Night-time delivery restrictions: a review. In: Taniguchi E, Thompson RG (eds) Recent advances in city logistics, proceedings of the $4^{\text {th }}$ international conference on city logistics. Elsevier, Amsterdam, pp 245-258

37. Quak HJ, de Koster MBM (2006) Retailer's distribution and local time window policies. In: Taniguchi E, Thompson RG (eds) Recent advances in city logistics: proceedings of the $4^{\text {th }}$ international conference on city logistics. Elsevier, Amsterdam, pp 463-478

38. Groothedde B, Uil K (2004) Restrictions in City-distribution and a possible alternative using the Citybox. In: Bovy PHL (ed.) A world of transport, infrastructure and logistics, 8th TRAIL congress 2004, DUP Science, Delft; pp 1-16

39. Anderson S, Allen J, Browne M (2005) Urban logistics - how can it meet policy makers' sustainable objectives? J Transp Geogr 13:71-81

40. Dutz, M. (2005). Road freight logistics, competition, and innovation: downstream benefits and policy implications. World Bank Policy Research Working Paper

41. European Communities (2006). Urban freight transportation and logistics. An overview of the European research and policy

42. Holguín-Vera J, Aros-Vera F, Browne M (2015) Agent interactions and the response of supply chains to pricing and incentives. Econ Trans 4(Issue 3):147-155

43. Gatta V, Marcucci E (2014) Urban freight transport and policy changes: improving decision makers' awareness via an agent-specific approach. Transp Policy 36:248-252

44. Lidasan HS (2011) City logistics: policy measures aimed at improving urban environment through organization and efficiency in urban logistics systems in Asia. Trans Commun Bull Asia Pacific 80:2011

45. Lindholm M (2013) Urban freight transportation from a local authority perspective - a literature review. Eur Trans 54 paper n3

46. Marcucci E, Musso E (2010) Urban freight modelling and policy analysis. In: Van de Voorde E, Vanelslader T (eds) Applied transportation economics. A management and Policy Perspective, de Boeck, Antwerpen

47. Quak HJ, de Koster MBM (2006) Retailer's distribution and local time window policies. In: Taniguchi E, Thompson RG (eds) Recent advances in city logistics: proceedings of the 4th international conference on city logistics, Elsevier, Amsterdam, pp 463-478

48. Van de Riet, O., de Jong, G. and Walker, W. (2008). Drivers of freight transportation demand and their policy implications

49. Visser J, van Binsbergen A, Nemoto T (1999) Urban freight transportation policy and planning. In: Taniguchi E, Thompson RG (eds) City logistics I, pp 39-70

50. Papoutsis K, Gogas M, Nathanail E (2012) Urban distribution concepts: a SWOT analysis on best practices of urban logistics solutions. 2nd International Conference on Supply Chains, October 5-6th, Katerini, Greece

51. Boerkamps J, Van Binsbergen A (1999) Goodtrip - a new approach for modelling and evaluating urban goods distribution. In: Taniguchi E, Thompson RG (eds) City logistics I. Institute of Systems Science Research, Kyoto, pp 175-186

52. Davis J (2014) Wal-Mart stores. Jefferies 2014 Global Consumer Conference. June 19, 2014, New York

53. Simon B (2013) Wal-Mart US. 20th Annual meeting for the investment community. October 15, 2013, New York

54. Baindur D, Macário RM (2013) Mumbai lunch box delivery system: a transferable benchmark in urban logistics? Res Transp Econ 38:110-121

55. Masson R, Trentini A, Lehuede F, Malhéné N, Péton O, Tlahig H (2013) Optimization of a city logistics transportation system with mixed passengers and goods. EMN Working Paper. Ecole des Mines de Nantes, France

56. Trentini A, Feliu JG, Malhene N (2015) Developing urban logistics spaces: UCC and PLS in South-Western Europe

57. Bickel P, Friedrich R (2005) ExternE. Externalities of energy. Methodology 2005 update. European Commission, Luxembourg

58. Blauwens G, De Baere P, Van de Voorde E (2012) Transport economics - fifth edition. De Boeck, Antwerpen
59. Macharis C, Van Hoeck E, Pekin E, van Lier T (2010) A decision analysis framework for intermodal transport: comparing fuel price increases and the internalisation of external costs. Transp Res A Policy Pract 44:550-561

60. Korzhenevych A, Dehnen N, Bröcker J, Holtkamp M, Meier H, Gibson G et al (2014) Update of the handbook on external costs of transport. DIW, CAU, Ricardo-AEA. https://ec.europa.eu/transport/sites/transport/files/handbook_ on_external_costs_of_transport_2014_0.pdf.

61. De Langhe K (2013) The importance of external costs for assessing the potential of trams and trains for urban freight distribution

62. Mayeres I, Ochelen S, Proost S (1996) The marginal external costs of urban transport. Transp Res Part D: Transp Environ 1:111-130

63. Beuthe M, Degrandsart F, Geerts JF, Jourquin B (2002) External costs of the Belgian interurban freight traffic: a network analysis of their internalisation. Transp Res Part D: Transp Environ 7:285-301

64. Gérard G, Struyf E, Sys C, Van de Voorde E, Vanelslander T (2015) Congestiekost voor wegvervoer: ontwikkeling generiek model en toepassing voor Vlaanderen. University of Antwerp. https://repository.uantwerpen.be/desktop/irua/core/ index.phtml?language=E\&euser $=\&$ session $=\&$ service $=$ opacirua\&robot $=$ \&deskservice=desktop\&desktop=irua\&workstation=\&extra=loi=c:irua:125580

65. Browne M, Allen J, Anderson S (2005) LEZs: the likely effects on the freight transport sector. Int J Log Res Appl 8:269-281

66. Kin B, Verlinde S, van Lier T, Macharis C (2016) Is there life after subsidy for an urban consolidation Centre? An investigation of the total costs and benefits of a privately- initiated concept. Trans Res Procedia 12:357-369

67. STRAIGHTSOL (2014). Deliverable D5.1 (demonstration assessments)

68. van Rooijen T, Quak H (2010) Local impacts of a new urban consolidation Centre - the case of binnenstadservice.NI. Proced Soc Behav Sci 2:5967-5979

69. Bjorklund M, Gustafsson S (2015) Toward sustainability with the coordinated freight distribution of municipal goods. J Clean Prod 98:194-204

70. Trentini A, Delaitre L, Malhene N (2010a) Evaluating the feasibility of shared passenger-goods urban transport solutions. 12th WCTR, July 11-15, Lisbon, Portugal

71. Trentini A, Mahléné N (2010) Toward a Shared Urban Transport System Ensuring Passengers \& Goods Cohabitation. Trimestrale del Laboratorio Territorio Mobilità e Ambiente - TeMA 3:37-44

72. Trentini A, Masson R, Lehuede F, Malhene N, Peton O (2012) A shared "passengers \& goods" city logistics system. 4th International Conference on Information Systems, Logistics and Supply Chain, Aug 2012, Quebec, Canada

73. Trentini A, Malhene N, Delaitre L, Boscacci F (2010b) A management model to plan and to control the coexistence of passengers and goods flow in the urban environment. Atti della XII Riunione 2010:1-23

74. Krajnc D, Glavic P (2005) A model for integrated assessment of sustainable development. Resources Conservation and Recycling 43:189-208

75. Yoon KP, Hwang CL (1995) Multiple attribute decision making, an introduction Quantitative applications in the social science series. Sage university paper. https:/onlinelibrary.wiley.com/doi/abs/10.1002/\%28SICl\%2910990771\%28199706\%2910\%3A2\%3C151\%3A\%3AAID-BDM265\%3E3.0.CO\%3B2-8.

76. https://www.slimnaarantwerpen.be/nl. Accessed 3 Mar 2016

77. https://www.viapass.be. Accessed 5 June 2016

\section{Submit your manuscript to a SpringerOpen ${ }^{\circ}$ journal and benefit from:}

- Convenient online submission

- Rigorous peer review

- Open access: articles freely available online

- High visibility within the field

Retaining the copyright to your article

Submit your next manuscript at $>$ springeropen.com 